\title{
Jejunum and Ileum Neuroendocrine Tumor TNM Finding v8
}

National Cancer Institute

\section{Source}

National Cancer Institute. Lejunum and Ileum Neuroendocrine Tumor TNM Finding v8.

NCI Thesaurus. Code C135093.

A finding about one or more characteristics of a jejunum and ileum neuroendocrine tumor, following the rules of the TNM AJCC V8 classification system. This classification system applies to small bowel "carcinoid" tumors (NET G1 and G2, and rare welldifferentiated G3) arising in the jejunum and ileum. This classification system does not apply to high-grade neuroendocrine carcinomas, mixed adenoneuroendocrine carcinomas, and neuroendocrine tumors of the duodenum. (from AJCC 8th Ed.) 